\title{
Investigation of outbreaks of Enterobacter aerogenes colonisation and infection in intensive care units by random amplification of polymorphic DNA
}

\author{
A. DAVIN-REGLI, P. SAUX*, C. BOLLET, F. GOUIN* and P. DE MICCO
}

Laboratoire d'Hygiene et de Microbiologie. Hôpital Salvator, 249 Bd Ste Marguerite, 13009 Marseille and *Département d'anesthésie-réanimation, Hôpital Ste Marguerite, 270 Bd Ste Marguerite, 13009 Marseille, France

\begin{abstract}
During a 4-month period, 41 isolates of Enterobacter aerogenes were cultured from different specimens from a 14-bed intensive care unit (ICU1). These were obtained from 12 patients out of a total of 187 patients admitted to the ICU. Sixteen E. aerogenes isolates were cultured from another ICU (ICU2) 6 months later. Six non-outbreakassociated strains were included as controls and all the isolates were compared by random amplification of polymorphic DNA (RAPD), with three different 10-mer oligonucleotide primers. The six non-outbreak-associated strains were distinguishable by RAPD with two of the three primers. RAPD fingerprinting with primer AP12h was as discriminatory as the combined results from all three primers and defined 22 different patterns for the 41 isolates from the ICU1. In nine instances, isolates with indistinguishable RAPD patterns were detected in two-to-five patients over a 3-15-day period, suggesting patient-to-patient transmission. During their stay in ICU1, patients harboured one-to-12 distinguishable isolates. Isolates from ICU2 were indistinguishable by RAPD analysis with the three different primers. These findings suggest that the cluster of colonisations and infections in ICU1 was a 'false outbreak', consisting of successive patient-to-patient transmission of different $E$. aerogenes strains. In contrast, the outbreak on ICU2 probably involved the extensive spread of a single strain.
\end{abstract}

\section{Introduction}

Until the 1980s, infections caused by Enterobacter aerogenes were relatively uncommon. However, according to recent National Nosocomial Infections Surveillance System data [1] Enterobacter spp. have replaced Klebsiella pneumoniae as the third leading cause of gram-negative nosocomial infections, particularly nosocomial pneumonias, after Escherichia coli and Pseudomonas aeruginosa [2-5]. Of particular concern is the ability of $E$. aerogenes to develop resistance to broad-spectrum $\beta$-lactam agents by the production of an extended-spectrum $\beta$-lactamase (ESBL) $[6,7]$. This species is part of the normal flora of the gastrointestinal tract and is, in some cases, a stable skin resident [8]. Reports concerning opportunist infections with $E$. aerogenes in hospitalised or debilitated patients first appeared in $1986[2,7]$.

Received 13 March 1995; revised version accepted 27 June 1995.

Corresponding author: A. Davin-Regli.
Consequently, all the studies concerning $E$. aerogenes nosocomial infections are recent [9-13]. Initial reports that described the spread of $E$. aerogenes strains involved two-to-five patients $[14,15]$. The investigation of apparent outbreaks of infection with $E$. aerogenes has been hampered by the lack of a sufficiently discriminatory typing method. Traditional techniques for typing $E$. aerogenes are based on phenotypic characteristics and include biotyping, O-serotyping, bacteriocin and phage typing. Unfortunately, biochemical reaction patterns are usually invariable among clinical isolates. Phage typing and serotyping are usually performed with $K$. pneumoniae reagents and are poorly discriminatory for $E$. aerogenes. Bacteriocin typing is useful but labour intensive, time consuming and limited to a few specialised centres [11]. Although DNA-based typing methods such as plasmid-profile analysis [13,16], ribotyping [17], small-fragment restriction endonuclease analysis and pulsed-field gel electrophoresis [18] have been used to differentiate isolates of $E$. cloacae, these techniques have not been applied to isolates from clusters of infection caused by E. aerogenes. 
A new DNA polymorphism assay was reported by Williams et al. [19] which is based on PCR amplification of random DNA fragments with short primers of arbitrary sequence. The resulting amplified fragments function as polymorphisms for DNA fingerprinting. In contrast to traditional target-specific PCR, no prior sequence information is required and the technique is potentially applicable to all bacteria. This technique has been applied successfully to epidemiological investigations of many bacterial genera and species [20]. In this report, the application of this random amplification of polymorphic DNA (RAPD) method to investigate the epidemiological relationship of isolates of $E$. aerogenes obtained from patients from two intensive care units is described.

\section{Materials and methods}

\section{ICU1 study}

Study population. An outbreak of E. aerogenes infection affecting 12 of 187 patients admitted to a 14bed Intensive Care Unit (ICU1) in Sainte Marguerite Hospital, between 17 Nov. 1992 and 3 March 1993 was studied in detail (Table 1). In these patients, the mean duration of hospitalisation and mechanical ventilation were 44 and 31 days, respectively, versus 8 and 5 days for non-infected or colonised patients. Infections were considered to be nosocomial when clinical source cultures were positive at least $48 \mathrm{~h}$ after admission.

Patient cultures. During the 4-month period of the study, 41 clinical isolates of $E$. aerogenes were obtained from the 12 patients on ICU1. The clinical specimens from which these were isolated included bronchial secretions, urines, closed cavity drainage specimens, catheters, vaginal samples, blood cultures and various wound swabs (from umbilicus, tracheostomy and drainage tubes). $E$. aerogenes was considered to be responsible for 10 infections: one bacteraemia, four pneumonias and five urinary tract infections and multiple colonisations. Between one and 16 isolates were studied from each patient, depending on the length of time the patient was hospitalised. Surveillance cultures were taken from patients within the first day of hospitalisation in the ICU and then once a week. Specimens from the rectum were obtained by Culturette swabs (Becton Dickinson and Co., Paramus, NJ, USA). Colonies were isolated on the selective medium Hektoen agar plates (bioMérieux, Marcy l'Etoile, France) as described previously [21]. All agar plates were incubated at $30^{\circ} \mathrm{C}$ for $24 \mathrm{~h}$. Blood

Table 1. Clinical details of patients on ICU1

\begin{tabular}{|c|c|c|c|c|c|c|c|}
\hline \multirow{2}{*}{$\begin{array}{l}\text { Patient } \\
\text { no. }\end{array}$} & \multirow{2}{*}{$\begin{array}{l}\text { Duration } \\
\text { of stay } \\
\text { (days) }\end{array}$} & \multirow{2}{*}{$\begin{array}{l}\text { Predisposing } \\
\text { factors }\end{array}$} & \multirow[b]{2}{*}{ Age/sex } & \multirow{2}{*}{$\begin{array}{l}\text { Underlying } \\
\text { disease }\end{array}$} & \multirow{2}{*}{$\begin{array}{l}\text { Infected/ } \\
\text { colonised } \\
\text { after (days) }\end{array}$} & \multicolumn{2}{|c|}{ Index of gravity } \\
\hline & & & & & & APACHE & SAPS \\
\hline 1 & 30 & $\begin{array}{l}\text { Ventilation } \\
\text { CV catheter } \\
\text { Corticosteroids }\end{array}$ & $51 / \mathrm{F}$ & $\begin{array}{l}\text { Asthma } \\
\text { Cardio-respiratory failure }\end{array}$ & $6^{*}$ & 28 & 14 \\
\hline 2 & 38 & $\begin{array}{l}\text { Ventilation } \\
\text { Urinary catheter }\end{array}$ & $53 / \mathrm{F}$ & Hepatectomy & $28^{*}$ & 19 & 18 \\
\hline 3 & 45 & $\begin{array}{l}\text { Ventilation } \\
\text { CV catheter }\end{array}$ & $55 / \mathrm{M}$ & Oesophagus surgery & $11^{*}$ & 30 & 11 \\
\hline 4 & 8 & $\mathrm{CV}$ catheter & $65 / F$ & Coma & 4 & 25 & 10 \\
\hline 5 & 51 & $\begin{array}{l}\text { CV catheter } \\
\text { Corticosteroids } \\
\text { Ventilation }\end{array}$ & $43 / \mathrm{M}$ & Respiratory failure & $39^{*}$ & 18 & 15 \\
\hline 6 & 7 & $\begin{array}{l}\text { CV catheter } \\
\text { Ventilation }\end{array}$ & $81 / \mathrm{M}$ & Peritonitis & $7^{*}$ & 35 & 17 \\
\hline 7 & 58 & $\begin{array}{l}\text { CV catheter } \\
\text { Haemodialysis } \\
\text { Urinary catheter }\end{array}$ & $58 / \mathrm{M}$ & $\begin{array}{l}\text { Nephrectomy } \\
\text { Cholecystectomy }\end{array}$ & $13 *$ & 19 & 15 \\
\hline 8 & 148 & $\begin{array}{l}\text { CV catheter } \\
\text { Ventilation } \\
\text { Urinary catheter }\end{array}$ & $45 / F$ & Peritonitis & $5+$ & 9 & 10 \\
\hline 9 & 65 & $\begin{array}{l}\text { Ventilation } \\
\text { Corticosteroids }\end{array}$ & $13 / F$ & Myasthenia & $54^{*}$ & 8 & 10 \\
\hline 10 & 77 & $\begin{array}{l}\text { CV catheter } \\
\text { Haemodialysis } \\
\text { Urinary catheter } \\
\text { Ventilation }\end{array}$ & $45 / \mathrm{M}$ & $\begin{array}{l}\text { Heart surgery } \\
\text { Acute renal failure }\end{array}$ & 49 & 12 & 13 \\
\hline 11 & 38 & $\begin{array}{l}\mathrm{CV} \text { catheter } \\
\text { Urinary catheter } \\
\text { Ventilation }\end{array}$ & $57 / \mathrm{M}$ & Moschcowitz syndrome & $30^{*}$ & 28 & 16 \\
\hline 12 & 7 & $\mathrm{CV}$ catheter & $65 / \mathrm{M}$ & Heart surgery & 1 & 11 & 5 \\
\hline
\end{tabular}

APACHE, acute physiology and health care evaluation.

SAPS, simplified acute physiology score.

$\mathrm{CV}$ catheter, central venous catheter.

* Patients considered to be infected.

†This patient had bacteraemia and pneumonia caused by E. aerogenes - isolates nos. 5 and 12 (Table 3), respectively. 
cultures were performed in a Bactec culture apparatus with 6A medium (Becton Dickinson).

Environmental cultures. Environmental samples from ICU1 were obtained three times during the 4month period (8 Dec. 1992, 10 Jan. 1993 and 6 Feb. 1993). Items used in patient care as well as those frequently handled by personnel were cultured. Samples were obtained with moistened Culturette swabs and plated on Bromo-Cresol Purple (BCP) agar plates (bioMérieux). Cultures from ICU1 health workers were obtained by pressing their fingers on to Mueller-Hinton agar supplemented with sheep blood 5\% (bioMérieux).

Antibiotic susceptibility testing. Antimicrobial susceptibility to 42 antimicrobial agents was determined by the standard disk-diffusion method on Mueller-Hinton agar (bioMérieux) (Table 2). The presence of ESBL activity was determined by placing disks containing cefotaxime, ceftazidime and ceftriaxone near a disk containing a $\beta$-lactamase inhibitor (sodium clavulanate $10 \mathrm{mg}$ and amoxycillin $20 \mathrm{mg}$ ). Extension of the zone of inhibition toward the disk containing clavulanate suggested the presence of an ESBL [22].

Identification. Biochemical reaction patterns (bioprofiles) were determined with the API $20 \mathrm{E}$ identification system (bioMérieux) according to the manufacturer's instructions.

\section{Other isolates}

Sixteen isolates from 10 patients associated with an outbreak of colonisation and infection with $E$. aerogenes between 21 Sept. and 14 Dec. 1993 in a different ICU (ICU2) in the same hospital were also investigated by RAPD analysis. These isolates were identified with the API20E and their antibiotic susceptibility was determined as above. As no regular epidemiological surveys were undertaken in ICU2, no environmental samples were obtained during this period.
Six non-outbreak-associated strains from our culture collection were included for comparison as controls for the RAPD method.

\section{RAPD analysis}

$D N A$ preparation. Isolates were grown overnight at $37^{\circ} \mathrm{C}$ on Mueller-Hinton agar (bioMérieux) and lysed as described previously [23]. Total DNA was isolated by a phenol-chloroform extraction method as described previously [23]. Briefly, bacteria were suspended in a solution of sucrose $25 \%, 0.01 \mathrm{M}$ Tris- $\mathrm{HCl}, 0.01 \mathrm{M}$ ethylene-diamine-tetraacetate (EDTA) and lysozyme (Sigma) $5 \mathrm{mg} / \mathrm{ml}$, pH 7.6, and incubated for $60 \mathrm{~min}$ at $37^{\circ} \mathrm{C}$. Sodium dodecyl sulphate $1 \%$ and proteinase $\mathrm{K}$ (Sigma) $0.5 \mathrm{mg} / \mathrm{ml}$ were then added and the suspensions were incubated at $60^{\circ} \mathrm{C}$ for $60 \mathrm{~min}$. Proteins were removed by four consecutive extractions with an equal volume of phenol:chloroform:isoamyl alcohol (25:24:1) and the total bacterial DNA was precipitated with ethanol $95 \%$ and dissolved in $10 \mathrm{mM}$ Tris- $\mathrm{HCl}(\mathrm{pH}$ 7.6), $0.1 \mathrm{mM}$ EDTA. The DNA was finally dissolved in water and concentrations were estimated on agarose gels.

Primers. All isolates were compared by RAPD with three different 10-mer oligonucleotide primers. The primers were those described by Williams et al. [19]: AP4, 5'(TCACGATGCA)3'; AP12h, 5'(CGGCCCC TGT)3' and AP13, 5'(ATTGCGTCCA)3'.

Amplification conditions. Amplification reactions were performed in a total volume of $47 \mu \mathrm{l}$ containing $100 \mu \mathrm{M}$ each of dATP, dCTP, dGTP and dTTP, $0.2 \mu \mathrm{M}$ of primer, $25 \mathrm{ng}$ of template DNA and 1.25 units of Taq polymerase (Perkin-Elmer/Cetus, Norwalk, CT, USA $)$ in $1 \times$ PCR buffer $(20 \mathrm{mM}$ Tris- $\mathrm{HCl}, \mathrm{pH} 8.3$; $50 \mathrm{mM} \mathrm{KCl}, 3 \mathrm{mM} \mathrm{MgCl}$, gelatin $0.001 \% \mathrm{w} / \mathrm{v}) . A$ negative control without template DNA was included in each experiment. The reaction mixtures were overlaid with mineral oil and amplified in a DNA thermal cycler (TR2, Cera-Labo, Aubervilliers, France) pro-

Table 2. Antibiotics used in disk-diffusion tests

\begin{tabular}{|c|c|c|}
\hline $\begin{array}{l}\text { benzyl penicillin } \\
\text { ampicillin } \\
\text { amoxycillin } \\
\text { ticarcillin } \\
\text { cloxacillin } \\
\text { methicillin } \\
\text { mezlocillin } \\
\text { piperacillin } \\
\text { ampicillin-sulbactam } \\
\text { amoxycillin-clavulanate } \\
\text { ticarcillin-clavulanate } \\
\text { piperacillin-tazobactam } \\
\text { imipenem } \\
\text { meropenem } \\
\text { aztreonam } \\
\text { trimethoprim-sulphamethoxazole }\end{array}$ & $\begin{array}{l}\text { cephalothin } \\
\text { cefamandole } \\
\text { cefoxitin } \\
\text { cefotiam } \\
\text { cefotaxime } \\
\text { cefsulodin } \\
\text { cefmenoxime } \\
\text { ceftriaxone } \\
\text { ceftazidine } \\
\text { cefpirome } \\
\text { cefoperazone } \\
\text { moxalactam } \\
\text { ceftazidime-sulbactam } \\
\text { cefoperazone-sulbactam }\end{array}$ & $\begin{array}{l}\text { erythromycin } \\
\text { spiramycin } \\
\text { clindamycin } \\
\text { rifampicin } \\
\text { neomycin } \\
\text { kanamycin } \\
\text { gentamicin } \\
\text { tobramycin } \\
\text { netilmicin } \\
\text { amikacin } \\
\text { streptomycin } \\
\text { fosfomycin } \\
\text { colistin } \\
\text { chloramphenicol } \\
\text { doxycyline } \\
\text { ciprofloxacin } \\
\text { pefloxacin } \\
\text { ofloxacin }\end{array}$ \\
\hline
\end{tabular}


grammed for 45 cycles of $1 \mathrm{~min}$ at $94^{\circ} \mathrm{C}, 1 \mathrm{~min}$ at $45^{\circ} \mathrm{C}$ and $1 \mathrm{~min}$ at $74^{\circ} \mathrm{C}$. Amplification products were compared by electrophoresis of $10-\mu \mathrm{l}$ samples in agarose $1.2 \%$ gels in Tris-acetate buffer $(0.04 \mathrm{M}$ Trisacetate, $0.001 \mathrm{M}$ EDTA, pH 8.2), stained with ethidium bromide and photographed on a UV light transilluminator. A molecular size standard (Marker VI, Boehringer-Mannheim, Mannheim, Germany) was included on each gel. Amplification patterns differing by two or more bands were considered to represent different strains. The reproducibility of the technique was determined by testing all isolates on at least three separate occasions with each RAPD primer.

\section{Results}

Typing

All isolates of $E$. aerogenes from ICU1 and the nonoutbreak control strains exhibited the same biochemical reaction pattern (5105773). E. aerogenes strains from ICU2 exhibited the pattern (5105673). RAPD characterisation of the six non-outbreak-associated strains gave four distinct amplification patterns with primer AP4 (data not shown) and six distinct patterns with primers AP13 and AP12h (Fig. 1). The three primers successfully typed the 57 isolates from ICU1 and ICU2 and the reproducibility of the RAPD assays was good. No products were detected in the negative control tubes. RAPD patterns with primers AP4, AP13 and AP12h classified the 41 clinical isolates from ICU1 in 11,18 and 22 distinct types of $E$. aerogenes respectively (Figs. 2-5). There was good correlation between the results with the three primers, with AP12h providing the best discrimination between strains (Fig. 5). For example, strains 2 and 3 were identical with primers AP4 and AP13 but different with primer AP12h. Strains belonging to the same AP12h type always belonged to the same AP13 and AP4 type (e.g., isolates 28, 29 and 30 belonged to the same AP12h, AP13 and AP4 type). The 22 different types (types av) generated with $\mathrm{AP} 12 \mathrm{~h}$ were as discriminatory as the combined results from all three primers and were, therefore, used to compare isolates.

Between one and 12 strains, distinguishable by RAPD, were detected from each of the 12 patients on ICU1. The temporal and genotypic relationships between the different strains obtained from the 12 patients hospitalised in ICU1 are shown in Fig. 6. Nine different RAPD patterns were each associated with two-to-five isolates from different patients (Table 3), suggesting spread of these strains between patients. Cross-transmissions involved two to five patients over a 3-15-day period (Fig. 6). In one patient, mixed colonisation was observed. Patient 8 carried two or three different isolates on the same day, each at a different site (nasal fossae, abdominal drain and

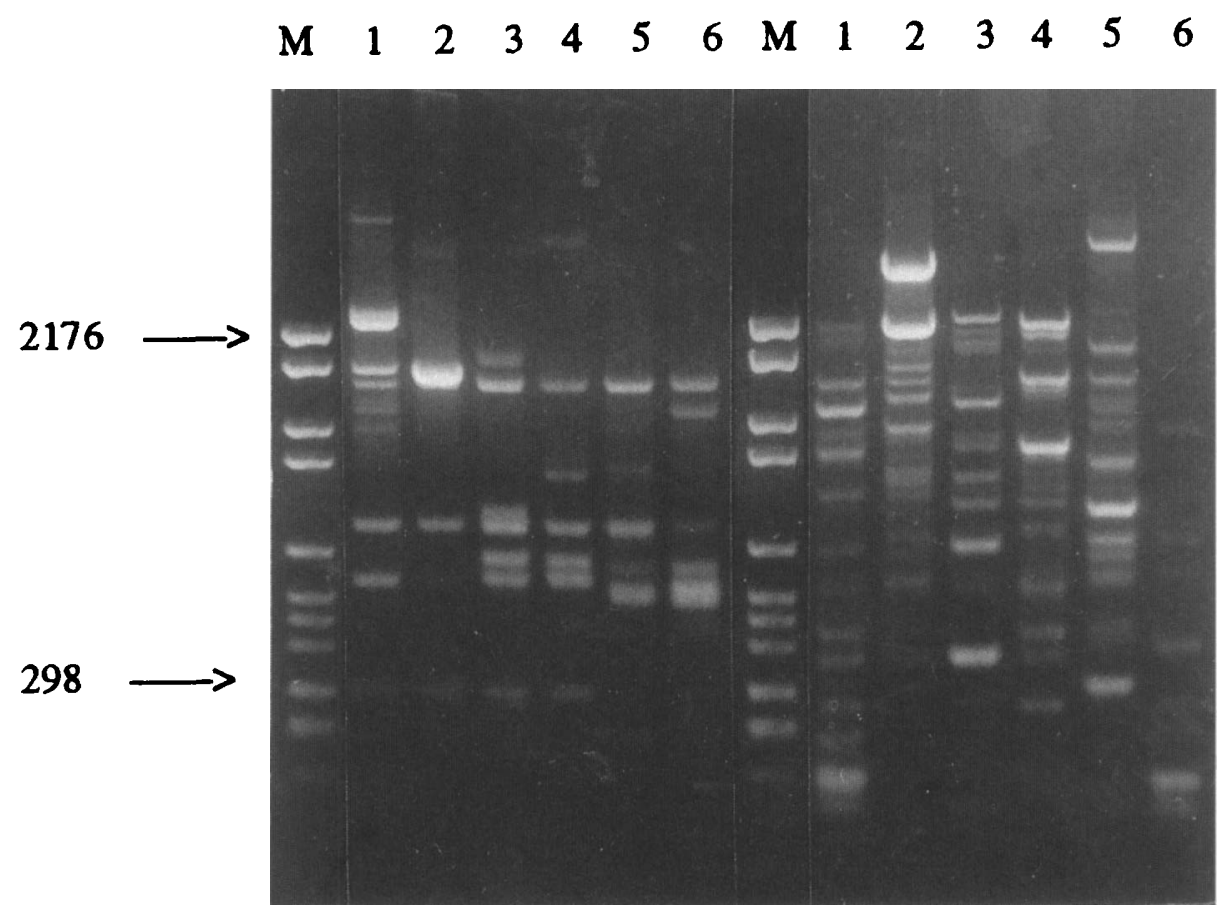

Fig. 1. RAPD patterns obtained with primer AP13 (left, lanes 1-6) and AP12h (right, lanes 1-6) for the non-outbreak control strains of $E$. aerogenes. Lane $\mathbf{M}$, molecular size standard. The sizes of the bands are shown in base-pairs. 


\section{I II III IV V VI VII VIII IX X XI $\quad M$}

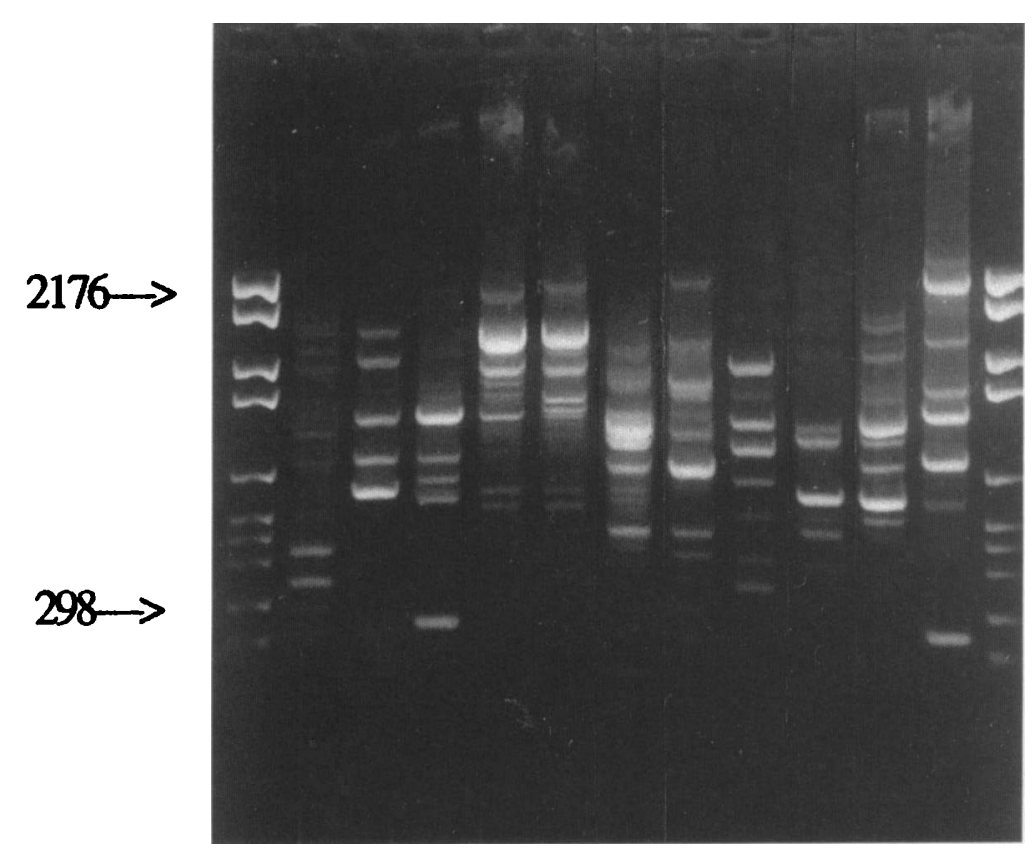

Fig. 2. The 11 RAPD patterns obtained with primer AP4 for E. aerogenes isolates from ICU1 (I-XI). Lane M, molecular size standard. The sizes of the bands are shown in bp.

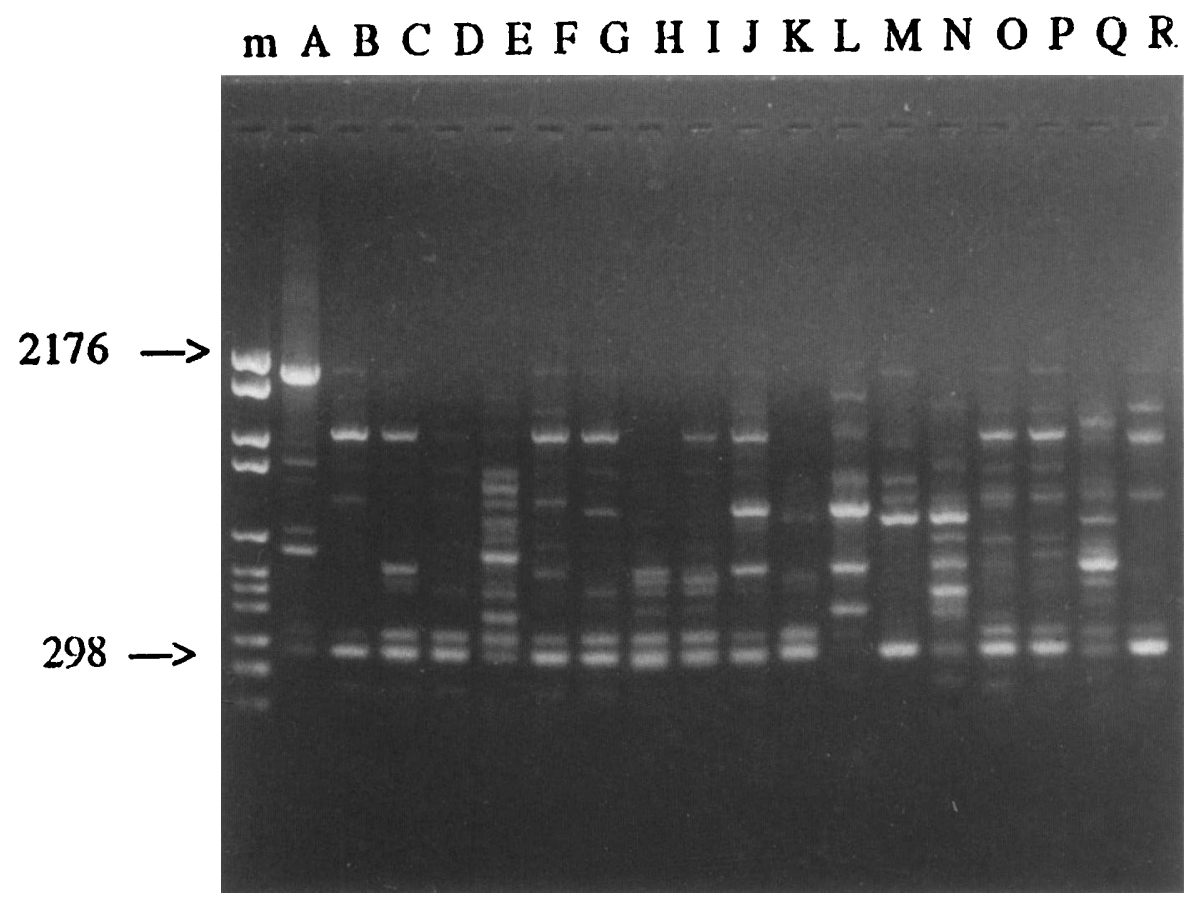

Fig. 3. The 18 RAPD pattern types obtained with primer AP13 for isolates of E. aerogenes from ICU1 (A-R). Lane M, molecular size standard. The sizes of the bands are shown in bp.

urinary tract). RAPD analysis of 10 separate colonies of $E$. aerogenes from single samples, showed that patients were colonised by a single clone of bacteria at a specific anatomical site at any one time. In all cases, the 10 colonies belonged to the same RAPDtype (data not shown).
An outbreak which had occurred in another ICU (ICU2) of the same hospital was also investigated. Which ever primer was used, the 16 strains studied gave very similar patterns (Fig. 4b). The RAPD patterns of the six non-outbreak control strains with primer AP12h were clearly different from 

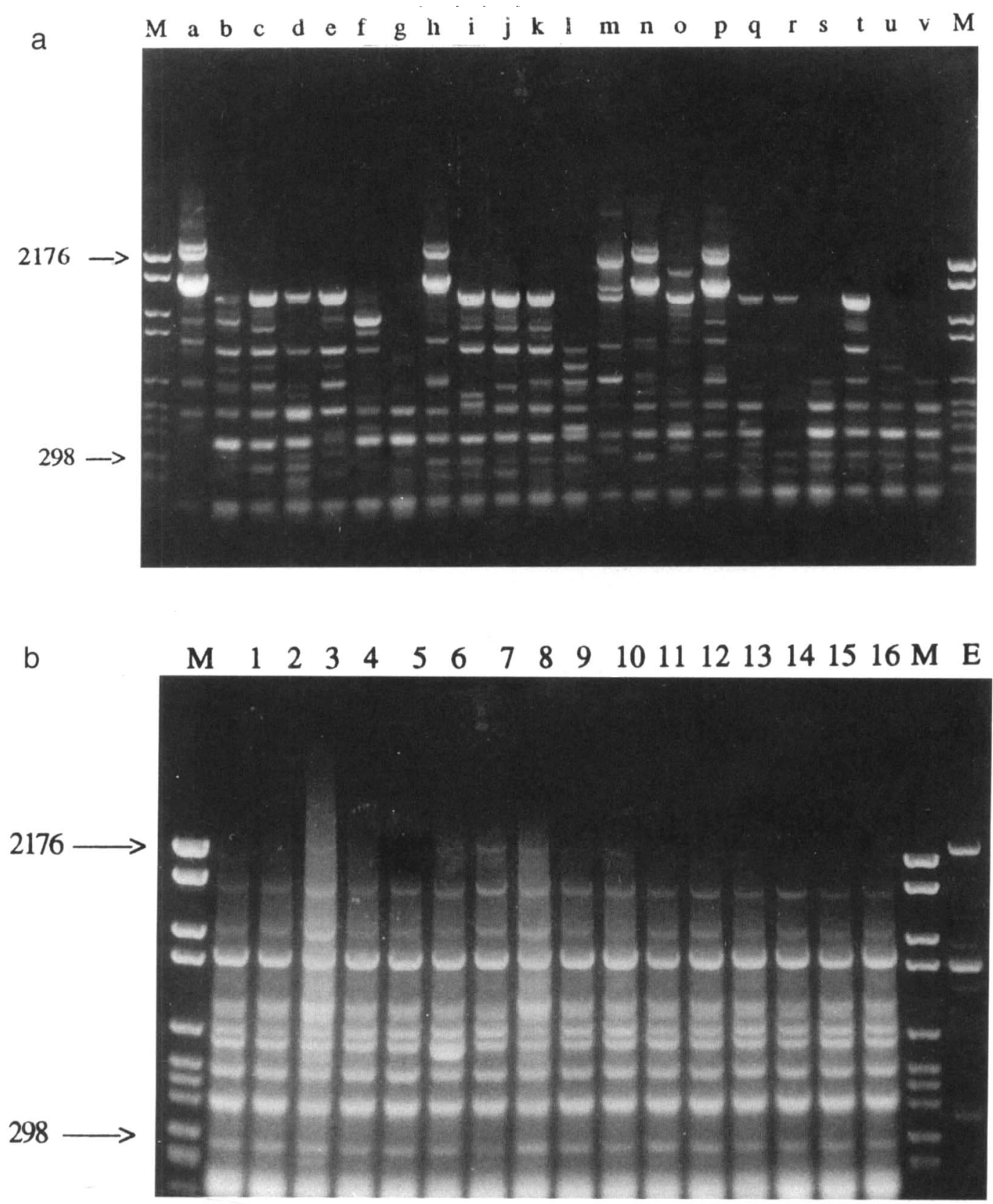

Fig. 4. Comparison between the RAPD patterns with primer AP12h of $E$. aerogenes isolates from ICU1 and ICU2. a, The different AP12h RAPD types of E. aerogenes isolates from ICU1, (a-v); b, RAPD profiles of E. aerogenes from ICU2 (lanes 1-16); $\mathbf{M}$, molecular size standard; the sizes of the bands are shown in bp; $\mathbf{E}$, environmental isolate from ICU1.

those obtained from the 41 strains from ICU1 and the 16 outbreak-related isolates from ICU2 (Figs. 1 and 4).

\section{Surveillance cultures}

Rectal colonisation with $E$. aerogenes was not found and $E$. aerogenes was not isolated from the hands of ICU1 health workers.

\section{Clinical co-infections}

In seven patients on ICU1, polymicrobial contamina- tions or infections involving two to six different microorganisms in a single patient were observed. In addition to $E$. aerogenes, $P$. aeruginosa was isolated in seven cases, Enterococcus faecalis in six, Staphylococcus aureus in three, coagulase-negative staphylococci from blood cultures in two and Streptococcus pneumoniae in bronchial secretions from two cases. In single cases, Esch. coli, Candida albicans, Stenotrophomonas maltophilia, Serratia marcescens (with ESBL) and Mycobacterium tuberculosis were isolated in addition to $E$. aerogenes. These results are similar to those obtained in a previous study [4]. 


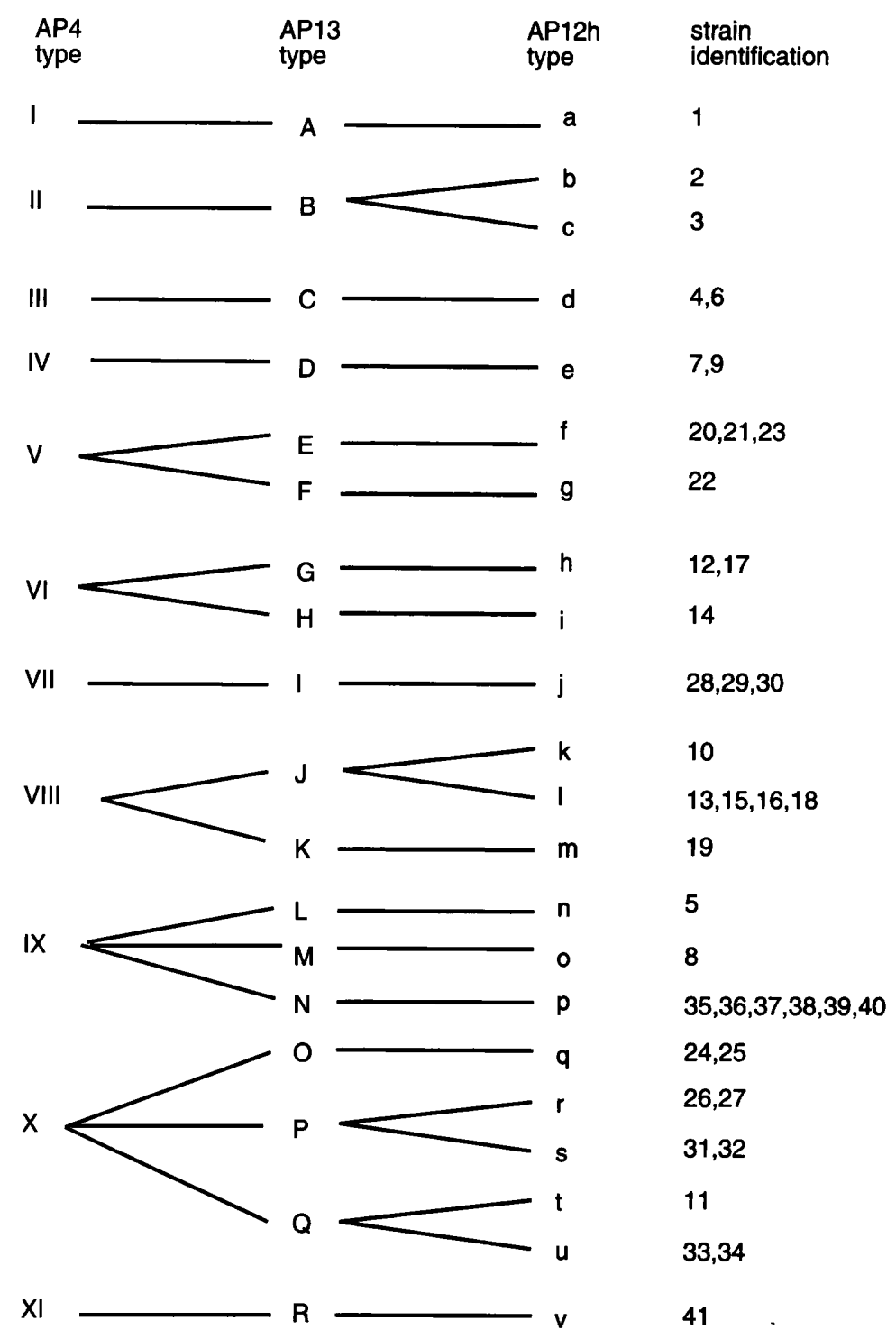

Fig. 5. Classification of the 41 isolates of $E$. aerogenes from ICU1 by RAPD patterns with three primers. The patterns obtained with the three primers AP4, AP13 and AP12h are numbered in roman numerals (I-XI), capital letters (A-R) and small letters $(\mathrm{a}-\mathrm{v})$ respectively. Isolates are identified by arabic numbers from 1 to 41 .

\section{Environmental data}

One strain of $E$. aerogenes was isolated from the humidifier of a mechanical respiratory device on ICU1, but this strain did not belong to an RAPD pattern found in clinical samples (Fig. 4, lane E).

\section{Antibiotic susceptibility}

The isolates from ICU1 had similar antibiotic susceptibility patterns, which indicated the presence of ESBL. Of the 41 isolates, 38 were susceptible only to imipenem, moxalactam, colistin and gentamicin. Three imipenem-resistant isolates were detected in urine and cutaneous samples in two patients. This resistance was associated with moxalactam resistance. Both urinary isolates appeared during the same week in two patients, but they were distinct by RAPD fingerprinting (isolates 25 and 27). Persistence of this type of resistance was not seen. The 16 isolates from ICU2 were susceptible to imipenem, cefotaxime, cefmenoxime, moxalactam, amikacin, gentamicin and colistin. No ESBL activity was detected in these isolates.

\section{Discussion}

In recent years, $E$. aerogenes has been recognised increasingly as a cause of bacteraemia and other serious infections in hospitalised patients. However, the epidemiology of this organism is still poorly understood. Some studies have reported that the most common portals of entry are respiratory (34-40\%), genitourinary $(27 \%)$, wound $(20-25 \%)$ and biliary $(18 \%)[2,4,10]$. One study considered the most common portal of entry to be abdominal (39\%), particularly after abdominal surgery, which is consistent with the enteric origin of Enterobacter spp. [13]. For the 12 patients from ICU1 in the present study, $60 \%$ were probably first colonised in the respiratory 


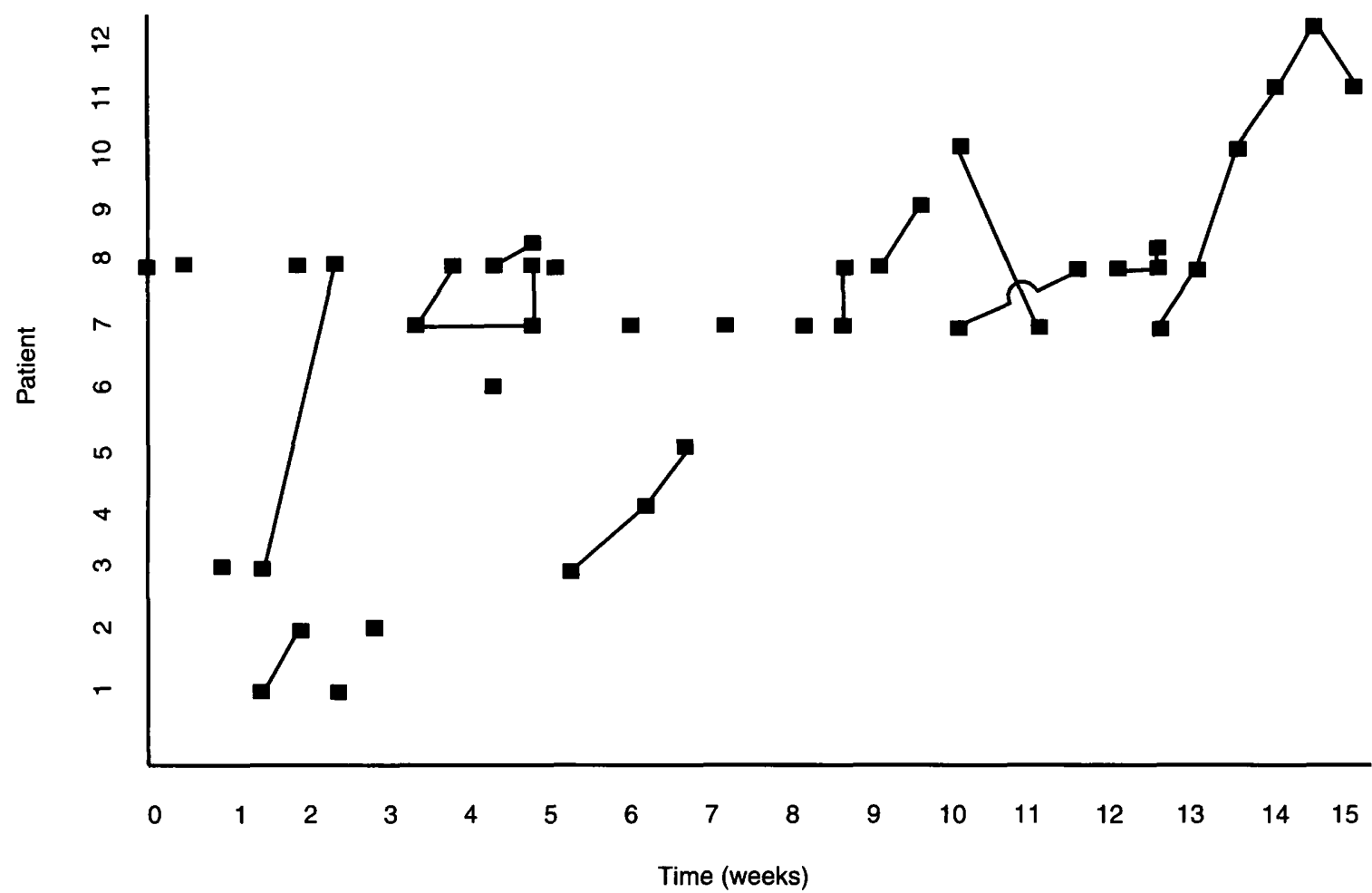

Fig. 6. Temporal and genotypic relationships between the 41 isolates of $E$. aerogenes obtained from the 12 patients hospitalised in ICU1. Strains with same AP12h RAPD type are joined by line and illustrate a possible order of transmission.

tract and $40 \%$ in the urinary tract. Endotracheal tubes and indwelling urinary catheters have been shown to be associated with Enterobacter bacteraemia [5].

The increase in prevalence of $E$. aerogenes has parallelled the intensive use of the expanded-spectrum $\beta$-lactam agents, particularly cephalosporins, in intensive care units $[12,24]$. Selection by these antibiotics favours the emergence of Enterobacter spp., whose presence in the gastrointestinal tract possibly serves as an endogenous source of infection $[14,22]$. Therefore, antibiotic treatment may lead to colonisation of the tracheobronchial tree and the skin by Enterobacter spp. with subsequent invasion promoted by respiratory failure, gastrointestinal tract operation or open skin wounds $[2,6]$. An endogenous source would explain why no common environmental source was detected in the present study. However, the protocol for collecting swab specimens from the rectum was not sufficently sensitive to confirm this, despite the use of a selective medium for the isolation of enteric pathogens of the family Enterobacteriaceae. The use of rectal swabs rather than stool cultures to determine colonisation would certainly lead to the underestimation of the number of patients who were colonised at the time of admission. E. aerogenes was not isolated from the hands of staff on ICU1, suggesting that horizontal transmission could not be explained by hand-carriage alone in this study. In previous studies, E. aerogenes has been isolated from contaminated instruments or solutions [14] and the present study detected an isolate from a humidifier. This was shown to be different from the clinical isolates by RAPD but the observation suggests that such items may act as a source of infection.

In the present study, three imipenem-resistant isolates were detected. The widespread use of imipenem in intensive care units is of concern as this selects imipenem-resistant isolates $[9,15]$. This resistance may be associated with a modification of a major outermembrane protein (OMP) $[15,25,26]$ or changes in lipopolysaccharide [27]. De Champs et al. observed an associated imipenem-moxalactam resistance in some isolates and the loss of this resistance at the end of imipenem treatment [15].

The present study raises the question of whether multiple colonisation involved sequential exposure to different strains or whether genotypic variations within strains were induced in vivo in response to changes in therapy. It is difficult to determine the role, if any, of antibiotic therapy in the evolution of different isolates of $E$. aerogenes. In patient no. 8, isolation of 12 different strains of $E$. aerogenes was concomitant with successive and major modifications in antibiotic therapy (Table 3). However, despite constant antibiotic therapy during a 42-day period for patient no 7 , five strains of $E$. aerogenes with very different RAPD patterns were isolated. Therefore, it seems unlikely that the two phenomena are related.

Because of the large number of $E$. aerogenes isolates from each patient on ICU1 and the relatively rare previous isolation of this species, together with the similar antimicrobial susceptibility patterns of the 
Table 3. Treatment and isolate details of patients in ICU1

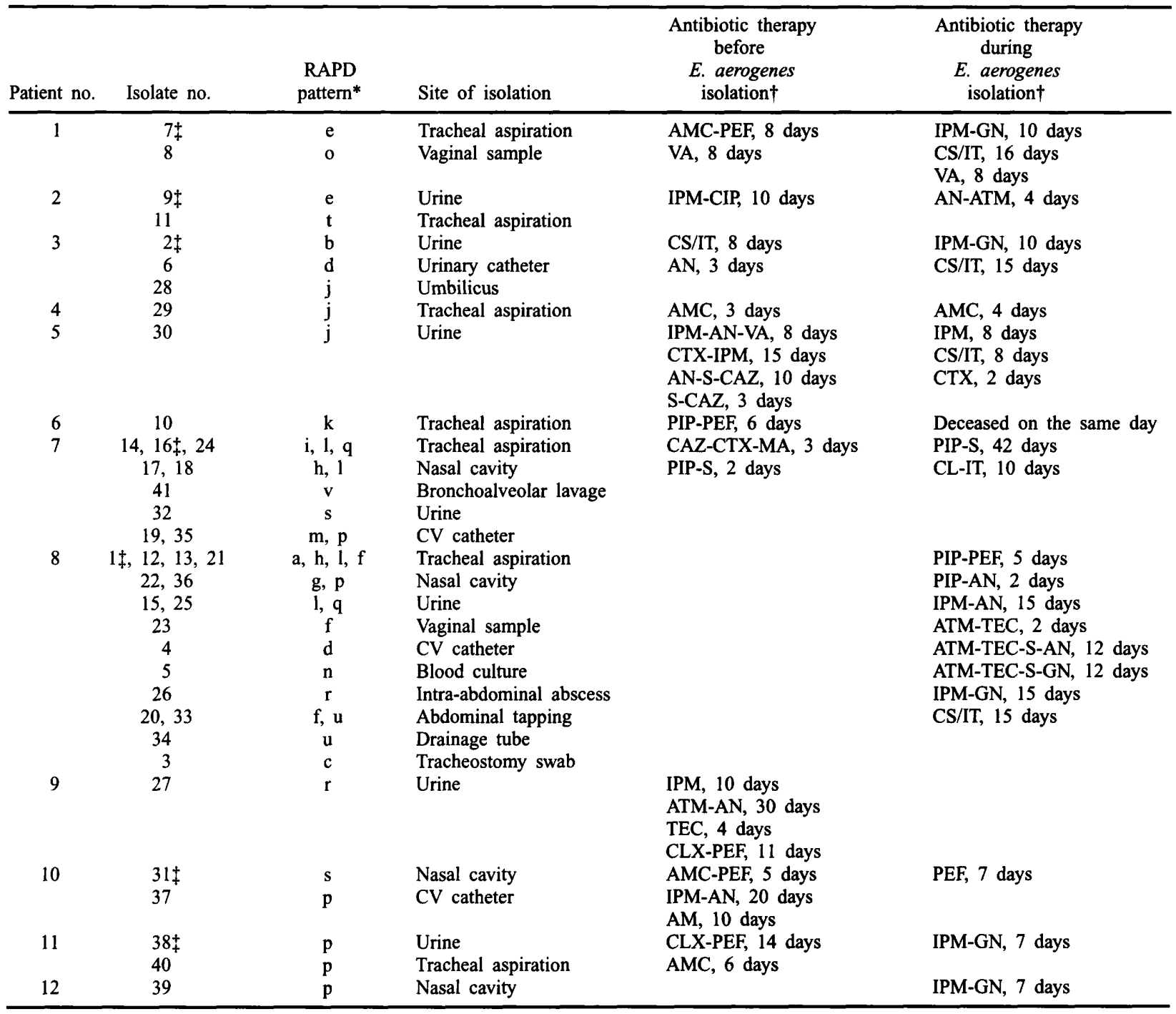

$\mathrm{CV}$ catheter, central venous catheter.

*RAPD pattern with primer AP12h as shown on Fig. 5.

†AMC, amoxycillin plus clavulanic acid; AM, ampicillin; AN, amikacin; ATM, aztreonam; CAZ, ceftazidime; CTX, cefotaxime; CS/IT, colistin intra-tracheal; CLX, cloxacillin; MA, cefamandole; CIP, ciprofloxacin; GN, gentamicin; IPM, imipenem; PEF, pefloxacin; PIP, piperacillin; S, sulbactam; TEC, teicoplanin; VA, vancomycin.

+Initial isolate from this patient.

isolates, it was thought initially that the outbreak was due to the spread of a single strain. However, the present study showed that several strains had spread between small numbers of patients. In some patients, isolates from different anatomical sites gave different RAPD patterns, suggesting carriage of multiple strains. We suggest that successive small outbreaks, as reported here, may be partly due to changes in the multiplication rate of strains. We suggest that the micro-organisms generally multiply at a low rate but this may increase for some reason, resulting in the spread of a micro-organism to several patients and possible infections. After transmission, the organisms may regress, leaving patients susceptible to colonisation and infection by other strains of $E$. aerogenes. In contrast to the situation in ICU1, a similar investigation in ICU2 revealed an outbreak that was probably caused by a single strain, although heterogeneity within this phenotype was not established and it is possible that the RAPD pattern represented a common type or clone.

The PCR-based DNA fingerprinting method termed RAPD is being used increasingly to discriminate between isolates within different species to trace transmission during outbreaks of infection in hospitals. In this study, RAPD analysis distinguished between a cluster of co-incident but independent infections and an . outbreak caused by a single strain. Therefore, RAPD is suitable for epidemiological studies of $E$. aerogenes and should also be applicable to investigations of other nosocomial infections.

\section{References}

1. Schaberg DR, Culver DH, Gaynes RP. Major trends in the microbial etiology of nosocomial infection. Am J Med 1991; 91: $72 \mathrm{~S}-75 \mathrm{~S}$. 
2. Burchard KW, Barrall DT, Reed M, Slotman GJ. Enterobacter bacteremia in surgical patients. Surgery 1986; 100: 857-862.

3. Gaston MA. Enterobacter: an emerging nosocomial pathogen. $J$ Hosp Infect 1988; 11: 197-208.

4. Watanakunakorn C, Weber J. Enterobacter bacteremia: a review of 58 episodes. Scand J Infect Dis 1989; 21: 1-8.

5. Weischer M, Kolmos HJ. Retrospective 6-year study of Enterobacter bacteraemia in a Danish university hospital. $J$ Hosp Infect 1992; 20: 15-24.

6. De Champs C, Sauvant MP, Chanal C et al. Prospective survey of colonization and infection caused by expanded-spectrumbeta-lactamase-producing members of the family Enterobacteriaceae in an intensive care unit. J Clin Microbiol 1989; 27: 2887-2890.

7. De Champs C, Sirot D, Chanal C, Poupart M-C, Dumas M-P, Sirot J. Concomitant dissemination of three extended-spectrum beta-lactamases among different Enterobacteriaceae isolated in a French hospital. J Antimicrob Chemother 1991; 27: 441-457.

8. Fawcett C, Chawla JC, Quoraishi A, Stickler DJ. A study of the skin flora of spinal cord injured patients. $J$ Hosp Infect 1986; 8: 149-158.

9. Ehrhardt AF, Sanders CC, Thomson KS, Watanakunakorn C, Trujillano-Martin I. Emergence of resistance to imipenem in Enterobacter isolates masquerading as Klebsiella pneumoniae during therapy with imipenem/cilastatin. Clin Infect Dis 1993; 17: $120-122$.

10. Gallagher PG. Enterobacter bacteremia in pediatric patients. Rev Infect Dis 1990; 12: 808-12.

11. Gaston MA, Strickland MA, Ayling-Smith BA, Pitt TL Epidemiological typing of Enterobacter aerogenes. $J$ Clin Microbiol 1989; 27: 564-565.

12. Weinstein RA. Endemic emergence of cephalosporin-resistant Enterobacter: relation to prior therapy. Infect Control 1986; 7 Suppl: 120-123.

13. Chow JW, Fine MJ, Shlaes DM et al. Enterobacter bacteremia: clinical features and emergence of antibiotic resistance during therapy. Ann Intern Med 1991; 115: 585-590.

14. Flynn DM, Weinstein RA, Nathan C, Gaston MA, Kabins SA. Patients' endogenous flora as the source of "nosocomial" Enterobacter in cardiac surgery. $J$ Infect Dis 1987; 156: 363368.

15. De Champs C, Henquell C, Guelon D, Sirot D, Gazuy N, Sirot $\mathrm{J}$. Clinical and bacteriological study of nosocomial infections due to Enterobacter aerogenes resistant to imipenem. $J$ Clin Microbiol 1993; 31: 123-127.

16. Markowitz SM, Smith SM, Williams DS. Retrospective analysis of plasmid patterns in a study of burn unit outbreaks of infection due to Enterobacter cloacae. J Infect Dis 1983; 148: 18-23.

17. Bingen E, Denamur E, Lambert-Zechovsky N, Brahimi N, el Lakany M, Elion J. Rapid genotyping shows the absence of cross-contamination in Enterobacter cloacae nosocomial infections. J Hosp Infect 1992; 21: 95-101.

18. Haertl R, Bandlow G. Epidemiological fingerprinting of Enterobacter cloacae by small-fragment restriction endonuclease analysis and pulsed-field gel electrophoresis of genomic restriction fragments. J Clin Microbiol 1993; 31: 128-133.

19. Williams JGK, Kubelik AR, Livak KJ, Rafalski JA, Tingey SV. DNA polymorphisms amplified by arbitrary primers are useful as genetic markers. Nucleic Acids Res 1990; 18: 6531-6535.

20. van Belkum A. DNA Fingerprinting of medically important microorganisms by use of PCR. Clin Microbiol Rev 1994; 7: 174-184.

21. Bollet C, Elkouby A, Pietri P, de Micco P. Isolation of Enterobacter amnigenus from a heart transplant recipient. Eur $J$ Clin Microbiol Infect Dis 1991; 10: 1071-1073.

22. Philippon A, Labia R, Jacoby G. Extended-spectrum betalactamases. Antimicrob Agents Chemother 1989; 33: 11311136.

23. Bassam BJ, Caetano-Anollés G, Gresshoff PM. DNA amplification fingerprinting of bacteria. Appl Microbiol Biotechnol 1992; 38: $70-76$

24. Olson B, Weinstein RA, Nathan C, Kabins SA. Broadspectrum beta-lactam resistance in Enterobacter: emergence during treatment and mechanisms of resistance. $J$ Antimicrob Chemother 1983; 11: 299-310.

25. Chow JW, Shlaes DM. Imipenem resistance associated with the loss of a $40 \mathrm{kDa}$ outer membrane protein in Enterobacter aerogenes. J Antimicrob Chemother 1991; 28: 499-504.

26. Hopkins JM, Towner KJ. Enhanced resistance to cefotaxine and imipenem associated with outer membrane protein alterations in Enterobacter aerogenes. $J$ Antimicrob Chemother 1990; 25: 49-55.

27. Leying H, Cullmann W, Dick W. Carbapenem resistance in Enterobacter aerogenes is due to lipopolysaccharide alterations. Chemotherapy 1991; 37: 106-113. 